\title{
Congenital microgastria
}

INSERM

\section{Source}

INSERM. (1999). Orphanet: an online rare disease and orphan drug data base. Congenital microgastria. ORPHA:199293

Cong enital microg astria is a rare malformation where the embryological development of the stomach is interrupted, leading to an abnormally small foregut in newborns and characterized by extreme feeding intolerance and malnutrition along with growth retardation and death if untreated. It is usually associated with multiple congenital anomalies. 